\title{
Cenas para pensar a educação na diferença ${ }^{1}$
}

\author{
Anelice Ribetto* \\ Carina Rattero ${ }^{* *}$
}

\section{Resumo}

Este ensaio se oferece como um exercício de escrita feito a quatro mãos como aposta política numa escrita coletiva e, também, apenas a duas mãos, como uma aposta e defesa da solidão da escritura. Ensaio composto por fragmentos que se enunciam na sua força expressiva como "cenas" que talvez permitam pensar a educação na diferença. Expressão de um bom encontro produzido entre duas professoras de universidades públicas - brasileira e argentina-que, atuando na formação de professores inicial e continuada ainda se perguntam pela possibilidade de criaçáo de uma cena educativa outra na qual se sacudam as práticas da mesmidade para apostar na irredutível irrupção de experiências contra hegemônicas. As cenas aquí apresentadas são um efeito de nossas inscursôes por diversas escolas públicas argentinas e brasileiras, conversas entre professores de universidades e escolas básicas e entre professores e alunos em formação, entre escolas e familias. Cenas que inspiram um ensaio que longe de apresentar resultados supostamente objetivos das nossas investigaçóes, mantém as preguntas e o campo problemático ascesso encharcado de interrogaçóes, irrupçóes e surpressas. Nada para ser seguido como modelo. Nada para ser contabilizado como dado. Apenas cenas entre educação e diferença. A primeira cena abre a pergunta: o que faz a escola com a diversidade? A figura escolhida para esta problematização é a dos que "desengonçam" a aula. A segunda cena se apresenta como uma crónica na qual o espaço da formação e a condição irredutível da diferença são testados e tensionados cotidianamente como um exercicio de invenção do nome dos outros.

Palavras-chave: Alteridade; Diferença; Outro.

* Professora doutora da Universidade do Estado do Rio de Janeiro, São Gonçalo, Rio de Janeiro, Brasil.

** Professora da Universidade Nacional de Entre Ríos, Concepción del Uruguay, Argentina. 


\section{Scenes to think education in difference}

\section{Abstract}

This rehearsal is offered as a writing exercise made four hands as political commitment to a collective writing and also only two hands like a bet and loneliness defense of scripture. Rehearsal consists of fragments that are enunciated in its expressive power as "scenes" that may allow think education on the difference. Expression of a good meeting produced between two teachers of public universities - Brazil and Argentina that, acting in the formation of initial and continuing teachers still ask for the possibility of creating an educational scene another in which shake the sameness practices to bet on irreducible irruption experiences against hegemonic. The scenes presented here are an effect of our incursions by various Argentine and Brazilian public schools, conversations between teachers from universities and basic schools and between teachers and students in formation between schools and families. Scenes that inspire a rehearsal that far from presenting results supposedly objective of our investigations, keep the questions and alight problematic field, drenched in questions, irruptions and surprises. Nothing to be followed as a model. Nothing to be recorded as given. Only scenes between education and difference. The First scene opens the question: what makes a school with diversity? The picture chosen for this problematization is the "gangling". The second scene is presented as a chronic in which the area for formation and irreducible condition of difference are tested and tensioned daily as an exercise of invention name of others.

Keywords: Aterity; Difference; Other.

\section{Os que "desengonçam"}

Hoje uma professora da pré-escola me disse: "esse aí veio me desengonçar a turma", termo que não tive coragem de pedir que ela traduzisse, mas que no contexto da conversa interpretei como sendo aquele que veio desorganizar aquilo que já estava encaminhado, o que estava armado de alguma maneira.

Adrián tem quatro anos, frequenta desde abril a sala da turma de quatro anos do horário vespertino. É o penúltimo de cinco irmãos, mora com a sua mãe, seu pai e um tio, irmáo do pai -para nós, e segundo o que as outras crianças falavam, esse tio pode fazer de pai, pode agir como se fosse o pai em ausência. O irmão mais velho frequenta a escola de Educação Integral da cidade e apresenta sérios problemas de conduta. O resto dos irmãos frequenta a nossa, "a comum", e o mais novo não vai à escola.

Adrián apresenta dificuldades de linguagem, mas consegue se comunicar às vezes com gestos e sons com os que, nas palavras da professora, "nem ele se entende, tadinho". A questáo é que desde abril até agora, por causa da sua chegada (por "culpa dele"), a turma ficou "desengonçada". O que fazer? 
$\mathrm{Na}$ voz da psicopedagoga contando a preocupação de uma professora, este relato traz à cena uma longa história de expulsão da diferença. Desenrola-se ali a fantasia de pensar que a turma seria um todo harmônico e sem conflitos se não fosse pela irrupção dos que desengonçam.

O componente dissonante, aquilo que vem alterar - desengonçar - uma ordem precária, uma aparente normalidade, é significado aqui como atributo desse sujeito particular. Assim, desde certas representaçôes essencialistas, monta-se uma construçáo de identidade como se a pobreza fosse do pobre, a violência do violento e a dificuldade de aprendizagem do aluno "problema". E como acontece com aquele do conto de Kafka, "Comunidade", "afastamo-lo, empurrando-o com o cotovelo, mas por mais que o façamos, volta outra vez".

Em consequência, estas representaçóes fazem supor que, expulsando o violento, acabaríamos com a violência. Expulsos os que desengonçam, ficaria reorganizada a turma. Expulso o lerdo, a turma ficaria homogênea.

É preferivel não explicar nada e não o aceitar. É que muitas vezes o olhar escolar transita entre perspectivas psicologistas, individualistas ou morais que ocultam ou disfarçam os efeitos devastadores da fragmentação social e econômica. Diferentes discursos e modalidades de intervenção parecem nos agasalhar contra aquilo que nossos próprios relatos deixam à mostra. Palavras como inclusão, diversidade, tolerância, respeito, vêm quebrar essa história, ou são só modos de calar a inquietude que o encontro com o outro produz em nós?

$\mathrm{O}$ que fazemos com os desengonçados e os que desengonçam? "Existem momentos na vida onde a questão de saber se se pode pensar diferente do que se pensa, e perceber diferentemente do que se vê, é indispensável (...) Se não consistir em tentar saber de que maneira e até onde seria possível pensar diferentemente em vez de legitimar o que já se sabe? Foucault (1984: 13) afirma nesta frase a aposta vital que acarreta esse gesto às vezes violento de problematizar o evidente. É que nas escolas, muitas situações que nos implicam, exigem hoje não só a busca de outras respostas, mas também nossa entrega à possibilidade de ensaiar um modo diferente de olhar e enunciar os problemas.

A modernização construiu diferentes dispositivos de regulação e controle da alteridade: a demonização do outro, o outro como fonte de todo mal (SKLIAR, DUSCHATSKY, 2001:188); visôes totalizadoras, lógicas binárias, localizaçóes que delimitam dentro ou fora da normalidade: bons e maus, certo ou errado, vigiar fronteiras, fabricar identidades fixas, estáveis, centradas, homogêneas.

Lembremos que, desde o século XIX, concebeu-se a escola como uma "tecnologia replicável e massiva para aculturar grandes camadas da população, similar às máquinas de tear que começavam a produzir têxteis em massa. Embora nem todas as pedagogias do século XIX coincidissem nesta metáfora -industrial ou tecnológicapara falar da escola (...) todas compartilharam o fato de conceber a escola como artefato ou invenção humana para dominar e encaminhar a natureza infantil" (PINEAU, DUSSEL e CARUSO, 2001: 22). 
Nesta escola nos formamos. Os tempos atuais albergam, no entanto, discursos e práticas confusas, clichês tranquilizadores de consciência, palavras que nos permitem conviver sem maiores conflitos num mar de supostos contraditórios.

Há um tempo, propus uma atividade a 300 professores com os que vínhamos trabalhando. Tentava-se recuperar o acervo circulante nas escolas, aquelas expressóes que evidenciam um modo de ver, de pensar e de se situar frente a estas palavras tão pronunciadas: homogeneidade, diferenças, atenção à diversidade. Deste modo, tentava construir coletivamente um campo de questóes para pensar. Compartilho alguns dos registros:

“Tem de se tirar a maçã podre" (Referindo a um menino "incontrolável”)

"Para que vêm na escola se não querem estar aqui? Não têm interesse em aprender"

"Esse aí não dá para esta escola" (Referindo a um menino com dificuldades de aprendizagem).

"Se a gente der uma vaga a esse aqui, vão embora os poucos bonzinhos que a gente tem"

"Eu tô falando, que quando vejo um menino, logo logo sei qual pode e qual não"

"Você vai ver, essa escola aqui é uma filial da Lucecitas" (Palavras de uma vice-diretora a uma professora recém-chegada)

"Mas, por que tem que vir na nossa escola? Por que acontece isso comigo? Esse ano tenho uma turma super homogênea?"

"A gente tinha que criar uma sala e botar ali todos os lerdos"

Muitas vezes, os educadores tachamos, desqualificamos ou violentamos desde certa moralização, desde o dever ser, ou desde certa representação do geral que encontra, no singular, só o desvio, seu fracasso. Trata-se de pensar como se constrói esta modalidade universalizante e corretiva. Explorar as próprias representaçôes e sensibilidades num gesto que tensione de um modo novo universalizaçáo e diferenças.

É que nossas representaçóes afetam não só a resposta que damos aos meninos, mas também o modo de organização institucional e o modo em que se dispóe e ordena a cena escolar. A todo custo, tenta se evitar a contaminação e a mistura. Prevenindo-se, a escola se priva do diálogo, do intercâmbio, do movimento... Justamente a escola, essa instituição que é o espaço para a construção do comum.

Em muitos casos, pelos tradicionais mecanismos discriminadores, como o preconceito ou a vontade corretiva, em outros, pela necessidade de encontrar soluçóes para os problemas cotidianos, a questáo é que continua se separando no interior da escola determinados grupos ou crianças que não respondem ao parâmetro ideal do aluno. Continua brilhando um modelo, a figura ideal do aluno: branco, disciplinado e piagetiano. 
Assim, todo aquele que mostre um sinal de risco, dificuldade, carência ou desvio, é alojado sob o manto da "atençáo à diversidade" 3. Sua inclusão se limita aos circuitos diferenciados da escola comum. Todos sabemos de que modo funcionam dentro das instituiçôes as categorias atribuidas a determinadas crianças (os do horário vespertino, os pobres, os lentos...).

Isso nos permite advertir mediante quais mecanismos a mesma operação que inclui produz suas formas específicas de exclusão, no oferecimento ou simples contenção. Os efeitos devastadores desta pedagogia são dissimulados naqueles discursos estigmatizadores de algumas infâncias e adolescências.

As identidades e diferenças são delimitadas como entidades fechadas, como se fossem um estado e não um modo de estar sendo num tecido de laços complexos, que são construídos e reconstruídos. Como consequência de uma cultura escolar homogeneizante, a resposta à demanda de "atenção à diversidade" pode, às vezes, reduzir-se a "tolerar" aqueles que mostram algum sinal diferencial, mediante a habilitação de um espaço que os recrute sem maior conflito.

De tal modo, a escola parece negar-se a considerar o incalculável como um espaço aberto à invenção de outros sentidos. E a resposta, em todo caso, cala, na continuidade do dado, qualquer sopro de possibilidade que aninhar entre as suas frestas.

Como recebemos e fazemos lugar a "esses que chegam nas nossas escolas"? ("esses” significa: outros setores estão chegando). Fazer lugar não é só oferecer uma carteira/uma vaga, uma matrícula, é alojar desde as próprias sensibilidades e representaçôes um horizonte de igualdade. Oferecer um espaço que potencie o aprender desafiando qualquer determinação confiscatória do futuro.

A escola é um local de encontros. Mas para que um encontro aconteça, há que ser capaz de calar em si próprios o próprio tumulto (o nhenhenhém, o preconceito, a pressa para localizar, diagnosticar, etiquetar), aprazá-lo por um instante para fazer lugar ao silêncio que, longe do vazio ou da renúncia, é disponibilidade e acolhimento . $^{4}$

Disponibilidade que recebe e oferece, isto é Ensinar. Organizar esta aposta inquietante do encontro com o desconhecido e oferecer o apoio necessário que o faça possível. Uma tarefa que, como menciona (MERRIEU; 2006: p. 27): "associa num único gesto, o saber e o seguimento. Um saber exigente, sem concessóes e um seguimento que permita a cada um ter acesso, utilizando os recursos de que dispóe."

Não há inclusão educativa sem reconhecimento simbólico.

O desafio hoje é pensar como enriquecermos o oferecimento educativo. $\mathrm{Na}$ tarefa de quem ensina a viver, há modos de responder eticamente à existência do outro, o que não significa só afirmá-lo na sua presença, porque a educação consiste em se encontrar de frente com o outro concreto, face a face (SKLIAR, 2011: 132). Não são eles, os recém-chegados, os que têm que se esforçar por se entrosar/encaixar, por não desengonçar o que já estava encaminhado. É nossa responsabilidade albergá-los. Fazer-lhes espaço é fazer possível o encontro com o saber, com o desconhecido, com a alteridade presente na construção do comum. 
Um professor é um inventor de mundos, um guardião do impossível (RATTERO, 2007, p. 9). Exercer como professores nos oferece esta possibilidade, a de habitar a pergunta pelo futuro sustentando uma ilusão. Essa mesma ilusão que dá consistência ao tempo vindouro, ou ao amor, essa que se doa sem pedir garantias. Um professor oferece signos, mundos, sinais, sentidos. Se ceder no diagnóstico ou na mera avaliação, fecha esse caminho de tempo e de habilitação.

\section{Formação na diferença e o invento dos outros}

Estava acompanhando um jogo no patio da escola especial na qual trabelhei durante dez anos em Argentina antes de morar no Brasil. Uma professora de uma escola regular que nos visitava se aproximou e me disse olhando para um dos meus alunos "Eu conheço esse aí. Foi meu aluno. Agora vocês tem na escola esse animalzinho?"

Um nome: animalzinho.

Um outro inventado a partir de uma das formas mais frequentes de narrar a alteridade: "o outro como fonte de todo mal" (SKLIAR e DUSCHATZKY, 2001, p.119) como uma sujeção dos sujeitos a certos estereotipos demonizados.

$\mathrm{O}$ animal: aquilo que representa uma alteridade radical. $\mathrm{O}$ que irrompe sem ser chamado "uma perturbação da mesmidade, um rosto que nos sacode éticamente" (SKLIAR, 2003, P.148) O imprevisivel, o perigoso, o que coloca o humano nos bordes da normalidade que transforma "o animalzinho" naquilo que é perigosamente anormal, pois "ao fazer de um desconhecido um conhecido anormal, a norma faz desse anormal mais um caso seu" (VEIGA-NETO, 2001, 113).

$\mathrm{O}$ aluno. $\mathrm{O}$ aluno de escola especial. $\mathrm{O}$ outro. $\mathrm{O}$ anormal. $\mathrm{O}$ animal. $\mathrm{O}$ nome.

O nome.

Contaram-me que quando Lube olhou o mundo pela primeira vez seus irmãos já saiam sozinhos. Que quando nasceu, vinha dentro de uma mesma bolsa junto com um gêmeo que não sobreviveu. Soube das suas alergias, e que por causa da fraqueza das suas pernas não podia dar nem dois passos e ficava olhando um mundo que parecia cheio de surpresas, fora desses dois passos. Falaram-me que náo foi negro de nascimento: osso e corpo descorado; que se prendeu ferozmente às tetas da sua máe, e, que sua mãe prendeu-se ferozmente à vida dele, e assim foram indo... É filho do melhor caçador que a vimos por aqui, ficou órfão num duelo de honra. Lube náo parecia ser nem macho nem fêmea, era só Lube. Soube que não pulava, nem brincava, nem emitia sons, nem ouvia: parecia não pertencer a este mundo, alheio na sua própria aventura de brigar com a vida dia a dia, náo fazia outra coisa que ser um lobisomem: o mais feio. Tampouco assistiu às aulas socializadoras com os irmãos, nem aprendeu das crises evolutivas normais, porque nunca as atravessou.

Será que como li em alguns textos um só pode ver quando acredita... ${ }^{5}$, que a isso que me contaram, o desejo, transformou fraquezas em fortalezas: hoje, depois de quase dois anos, eu olho 
Lube olhar o mundo com olhos abertos, e, ao mundo olhá-lo boquiaberto.

Seus irmãos cresceram e fugiram da casa para outros lugares e gentes, ele inventou-se um amigo invisível a quem conta nossos contos quando nos dormimos. Não sabe de gêmeos, nem de irmãos, nem de humanos: Lube é uma relaçáo em si mesmo, e é onde ele circula para dizer que alguém está ali, pretendendo ser nomeado para constituir-se. Já não espirra, mas alguma alergia está transformando-o num careca novo. Não tem feito muito mais que dois passos... e, acredita que pisou a lua: ele só reconhece como próprio o quintal onde marcou limites que permitem a ele, seguir sendo, sempre em referencia a outros; no seu quintal de um pouco mais de dois passos, Lube inventa espaços onde nos permite rir de nós mesmos inventando seus lugares de crescimento. Lube é negro agora, mas tem brilhos vermelhos; segue sendo pele e ossos, porem ele não tem complexos em seu desengonçado andar nem em sua cor indefinida. Abandonou a teta da sua mãe, porem ela não parou de amamentá-lo dessa cálida presença que têm as madrazas de todas as culturas: seu olhar fica sempre atento à maneira em que Lube é testemunho da sua teimosa generosidade. Para contrariar as expectativas de seu pai, só caça borboletas que sempre voam longe. Cuida, mais que nada, dos dois saquinhos inchados que penduram de suas pernas e que ainda náo descobriu os prazeres que podem dar-lhe, os exibe, mostrando aos quatro ventos que ele foi ele desde o começo, pena que nós não sabíamos disso. De lobisomem virou Lube com lua cheia e sem se olhar em outros espelhos.

Dizemos que ele é o cangaceiro mais bem-humorado de uma quadrilha de outros nomeados, que o nomeiam, e nessa relação dialógica tem se dado à vida: nunca soubemos como foi que, Lampião, seu irmão, com um só olho, começou a seguir seus passos e a salvá-lo de cobras que não pretendiam brincar de guerra com ele. A Pirrila, divina do clan, santa e vagabunda, caçadora e cassada, ágil e mansa, empenha se em trazer ao terceiro mundo, descendência que o encha; essa descendência teimosa emerge desde relaçóes que jamais podemos terminar de entrelaçar ou controlar, porque se escorrem como seu andar. Luis Melodia, tem nome que o define: maldito, negro, ágil, abusado, inteligente, sonoro; Melodia iniciou a Lube num mundo de amigos reais, dando-lhe possibilidades de fazer visível isso que estava invisível como um amigo no mato; Lube, grandalhão sentado na ultima fila da sala de aulas faz só garrancho, enquanto Melodia constrói teoremas de científicos loucos. Birdy é dois: um que foi ao vazio, e outro que se incluiu no clan: branco, olhos azuis, filho de pai estrangeiro. Qual é a hierarquia entre eles? Quem é quem ali onde se encontram?

Finalmente, Lube, tem mais de sete vidas... e as desfruta dia por dia, nem sabendo que poderia antecipar saudades e perdas, felicidades e amores... só vai vivendo todas ao mesmo tempo.

Lube, suspeitarão, é um GATO, eu não sei se ele sabe que é um gato, mas de alguma maneira reconhecemos a necessidade apren- 
dida de encaixá-lo numa categoria que o identifique: nos serve ao nosso controle... não sei se serve a ele... então, Lube é nosso gato e ao mesmo tempo, não é... li uma frase da escritora Clarice Lispector que fiz minha, em algumas oficinas sobre Inclusão escolar que coordenei numa escola do Rio de Janeiro, quando debatia com os professores sobre a constituição relacional do outro e, sobre o próprio e interno outro que inventamos quando nomeamos ao aparentemente alheio e estranho outro; Clarice dizia "Eu reduzida a uma palavra? Porém, qual palavra me representa? Uma coisa sim que eu sei é que eu não sou meu nome. Meu nome pertence aos que me chamam." (LISPECTOR, 1991, p. 37).

$\mathrm{O}$ aluno. $\mathrm{O}$ aluno de escola especial. $\mathrm{O}$ outro. $\mathrm{O}$ nome.

O nome.

\section{A duas vozes: ensaiando possibilidades outras...}

... Para tentar resistir a certas posiçôes hegemônicas que produzem efeitos subjetivantes dolorosos para muitos dos habitantes dos territórios escolares.

Nomes e contornos tentam delimitar e fixar a identidade, cancelando o possível, o que muda,o devir. No entanto, "não há nada que não tenha seu é, nem nada que não tenha seu pode ser. E o é de cada coisa não é outra coisa senão o nome assumido para ela, enquanto seu pode ser dorme no seu interior à espera de que o estabelecimento de um novo nome para ela o acorde." (LIZCANO,2009, p.124) A educação precisa recuperar para si esse olhar de implicação e empatia, um olhar que desperte o pode ser no interior do nomeado...problematizar em cada um de nós essas políticas desde as que percebemos ou invisibilizamos alguém, essas fixaçóes nas que repousa uma ordem excludente e estigmatizadora (RATTERO, 2011, p. 81)

Para recuperar esse olhar talvez precisemos problematizar o que a escola é como espaço comum, como espaço para "estarmos juntos" (SKLIAR, 2010, p.101): um território que não seja pensado e praticado livre de conflitos, de tensôes, mas que, transforme as tensóes no próprio exercício de problematização da vida escolar como um modo de exercitar o comum, o que é de todos.

Isso também implica problematizar o acolhimento do outro, um acolhimento que é, se pensado apenas como um movimento de mão única e sem esforços de deslocamentos relacionais, apenas uma caricatura do que instituímos como políticas da hospitalidade. O convívio é atrito. O que fazemos com isso? Quando chega um aluno que nos coloca nesse lugar incômodo/desconfortável, a prática mais frequente é a tentativa de acabar rapidamente com aquilo que nos interpela: seu mistério. Certos movimentos sáo habituais como modo de acalmar a inquietude que esse encontro com o desconhecido nos provoca: nomear, classificar, conhecer, rotular. Naturalizouse essa urgência em transformar o outro que chega com sua alteridade radical em outro familiar (SKLIAR, 2010, p. 80). Domesticado. Nomeado, etiquetado "Nunca deixamos de encaminhar o desconhecido ao conhecido, de fatiar o mistério para clareá-lo. Nomeá-lo" (DOUFOURMANTELLE,2003, p.31) Mas, esta operação nunca é tranquila. O outro teima em seguir sendo, nem que seja na intimidade mais recôndita, fatalmente outro. E aí está a resistência. A vida... 
A 'objetivação do sujeito' vai produzindo um olhar sustancializador do aluno (definido como carente, especial, perigoso, violento, pobre). Este modo de se situar frente o outro produz um diagrama em que os lugares ficam determinados, de modo tal que fica impossível ver outras possibilidades nas quais se aventurar, não inclusas, ou náo antecipadas nas linhas que esta topologia determina. (RATTERO, 2009, p.181).

Em algum sentido, as cenas propostas oferecem pensar o próprio olhar. Os relatos revelam essa riqueza e contribuem, pela sua vez, para pensar os avatares de una prática sempre afetada, exposta à travessia, àquilo que porta o risco de se saber vulnerável no que cada um passa, pensa, sente no dia-a-dia... Quiçá por isso convidam,mais uma vez, para o trabalhoso devir do pensamento, quando do que se trata é de pensar algo que não é alheio, mas a própria experiência.

Se a possibilidade de uma experiência supõe a suspensão de uma série de vontades: a vontade de identificar, a vontade de representar, a vontade de compreender. Estamos disponíveis para darmos acolhimento a esse outro sem intento de captura?

Em cada cenário educativo, de diferentes modos, essas vontades costumam aparecer, no mesmo momento em que as diferenças são nomeadas: "o diferente" - "o desengoçador", "o gato", "o bichinho", ou "aquele que não dá". Como efeito desse olhar, desse modo de nomear como exercício de uma exterioridade, esse outro - "o diverso"-alude àquele que não pode ser visto, nem nomeado, que não poderia ser percebido, aceito, recebido nem educado. Trata-se, ante de mais nada, de identifica-lo, fazê-lo enunciável, de registrar, detectar e diagnosticar.

Como aquele que não cabe num horizonte em que não há lugar para o devir do incalculável, porque espera a mesmidade, o homogêneo, o que não desborde o esperável, só aparece como objeto da ação pedagógica sob as formas da reparação, do conhecimento ou a integração.

No entanto, a diferença está aí (SKLIAR, 2011, p.100) Entre.Não numa coisa, num conceito, num sujeito em particular. Não num sentido essencial, mas relacional. Por isso, a decisão acerca de como nos encontramos, acerca da disponibilidade para esse encontro é sempre política, é sempre um gesto, um modo de responder eticamente a sua presença.

Qual é nossa experiência no vínculo com a alteridade? Suportamos a irrupção do outro na sua radicalidade? Nossos modos de olhar e de nomear podem desencadear consequências incalculáveis na vida de alguém. Tratar-se-ia, então, de habilitar um espaço para a surpresa, de evitar esses "olhares que mancham" (SKLIAR, 2008) Não como práticas essencializadoras e acabadas, mas, como esses pequenos gestos produzidos cotidianamente que materializemos deslocamentos que mutuamente nos provocamos quando apostamos em relações que mantêm a diferença e, ao mesmo tempo,nos colocam disponíveis para criar projetos em comum, albergando diferenças e intensidades, pluralidade de cores e formas, num modo de pensar e fazer educação.

Seremos capazes de olhar com olhos novos? Poderemos abraçar eticamente os nossos alunos? Seremos capazes de nos olharmos eentre-olharmo-nos? 
Olharmo-nos. Entre-olharmo-nos e abraçarmo-nos eticamente como resistência, como produçâo de vida e diferença. Cuidar o mistério. Porque

parece(-nos) que a educação não é o lugar adequado para estar sempre nos perguntando quem somos? Nem sobre nossa identidade. A educação pode ser também um lugar para nos perguntarmos como comunicar ou transmitir a, como conversar com, desconhecidos (...) Algumas vezes me pareceu detectar, nos rostos daqueles com quem exerci a profissão de educador, uma espécie de desafio: "Não tente adivinhar quem sou, o que quero, desde onde falo. Não tente buscar categorias que me encerrem. Não se esforce por me classificar de nenhuma maneira. $\mathrm{O}$ que conseguirá com isso? Me entender melhor? Me educar melhor? Náo perca meu tempo e suas energias tentando compreender quem sou. Sou qualquer um. (MOLINA GARCIA, José, 2008, p.200-201).

\section{Referências}

DUFOURMANTELLE, A. Convida Jacques Derrida a falar da hospitalidade. São Paulo: Escuta, 2003

FOUCAULT, M. Estética, ética y hermenéutica, obras escenciales. Volumen III. Buenos Aires: Paidós Básica, 1994

LISPECTOR, C. Um Sopro de vida. São Paulo, Francisco Alves: 1991 ( $9^{\circ} \mathrm{ed}$.)

LIZCANO, E. Metáforas que nos piensan. Sobre ciencia, democracia y otras poderosas ficciones. Buenos Aires: Biblos, 2009

MEIRIEU, P. Cartas a un joven profesor. Pro qué enseñar hoy. Buenos Aires: Grao, 2006.

MOLINA GARCÍA, J. Imágenes de la distancia. Barcelona: Editorial Laertes, 2008

PINEAU, P. DUSSEL, I. E CARUSO, M. La escuela como maquina de educar. Tres escritos sobre un proyecto de la modernidad. Buenos Aires: Paidos, 2001.

RATTERO, C. Habitar la pregunta: notas en el vínculo infancia y educación. In: DOVAL, D.; RATTERO, C. (comps.) Autoridad y transmisión: niños y jóvenes en la mira. Buenos Aires: Noveduc, 2011.

RATTERO, C. Ser maestro ¿̨vale la pena? Ministerio de Educación Ciencia y Tecnología. Argentina, 2007. Disponível em: <http://www.me.gov.ar/curriform/publica/sermaestro_vale.pdf>. Acesso em: 6 out. 2014.

RATTERO, C. La pedagogía por inventar. IN: SKLIAR, C.; LARROSA, J. (comp) Experiencia y alteridadeneducación. Buenos Aires: Ed. Homo Sapiens, 2009

SKLIAR, C e DUSCHATZKY, S. O nome dos outros. Narrando a alteridade na cultura e na educação. In: SKLIAR, C.; LARROSA, J. Habitantes de Babel. Políticas e Poéticas da Diferença. BH: Ed. Autentica, 2001.

SKLIAR, C; LARROSA, Jorge. Habitantes de Babel. Barcelona: Leartes, 2001.

SKLIAR, C. Entrevista. 2008. Disponível em: <http://www.noveduc.com/index.php>. Acesso em: 30 nov. 2014.

SKLIAR, C. Los sentidos implicados enel estar-juntos de laeducación. Revista Educación y Pedagogía, vol. 22, núm. 56, jan./abr. 2010.

SKLIAR, C. Pedagogia (improvável) da diferença. E se o outro náo estivesse aí? Rio de Janeiro: DP\&A, 2003.

SKLIAR, C. Lo dicho, lo escrito, lo ignorado. Ensayos mínimos entre educación, filosofía y literatura. Buenos Aires: Miño y Davila, 2011.

VEIGA-NETO, A. Incluir para Excluir. IN: SKLIAR, C.; LARROSA, J. Habitantes de Babel. Políticas e Poéticas da Diferença. BH: Ed. Autentica, 2001. 


\section{Notas}

${ }^{1}$ Tradução e Revisão: Prof. Juan José Rodriguez (UNC).

${ }^{2}$ Lucecitas é o nome de uma escola.

${ }^{3}$ Como assinaláramos em diversas oportunidades, sob a denominação de necessidades educativas especiais se recruta nos "circuitos integradores" da escola uma grande quantidade de crianças (pobres, diferentes, "portadores de deficiência", carentes, etc.) que fracassam como consequência de uma cultura escolar homogeneizante e seletiva.

${ }^{4}$ Vid e Rattero, C.(2011). "Habitar la pregunta: notas en el vinculo infancia y educación”. En:DOVAL, D. Y RATTERO, C.(comps.) Autoridad y transmisión: niños y jóvenes en la mira.Buenos Aires: Noveduc.

${ }^{5}$ Humberto Maturana, Heinz Von Foerster, “don Juan” de Carlos Castañeda.

\section{Correspondência}

Anelice Ribetto - Universidade do Estado do Rio de Janeiro, Faculdade Formaçáo de Professores. Rua Dr. Francisco Portela, 1470, Patronato. CEP: 24435005. São Gonçalo, Rio de Janeiro, Brasil.

E-mail: anelatina@gmail.com - carina.rattero@hotmail.com

Recebido em 10 de maio de 2016

Aprovado em 11 de julho de 2016 
